\title{
Students' Attitudes to Universal Design in Architecture Education
}

\author{
Helen Larkin \\ Deakin University \\ Kelsey Dell \\ Deakin University \\ Danielle Hitch \\ Deakin University
}

\begin{abstract}
It is widely recognised that the built environment can dramatically impact on the participation and engagement of people with disability and diverse needs. It has therefore become necessary for architects and designers to consider these needs when working within their profession. The implementation of universal design teaching into architecture and design curriculum has been recognised as an important step in facilitating and enhancing the uptake of universal design during the design process. Using a quantitative approach, this study aimed to compare, contrast and explore the attitudes of two groups of architecture students to the universal design of built environments. One group had received education relating to diversity and universal design as part of a prior project while the other group had not received this content. Findings from this study demonstrated that while there were no significant differences between the two groups, interesting insights and perspectives emerged regarding student attitudes to universal design and the potential influencers of these attitudes.
\end{abstract}

Keywords: Universal Design, Architecture, Curriculum, Higher Education, Built Environment

The International Classification of Functioning, Disability and Health (ICF) "acknowledges that every human being can experience a decrement in health and thereby experience some disability" (World Health Organization [WHO] 2002, p. 3). It is now widely recognised that the physical or built environment can dramatically impact the participation and engagement of people with diverse needs, via the inclusion in the ICF of environmental contextual factors (WHO, 2013).

This issue has been acted upon through the United Nations Convention on the Rights of Persons with Disabilities where Article 9 specifically requires signatories to eliminate environmental obstacles and barriers (United Nations, 2006), however the implementation of this convention has not been complete. For example; more than $27 \%$ of respondents in an Australian study stated the built environment was a barrier to their full participation in the community (National People with Disabilities and Carer Council, 2009).

Corresponding author: Helen Larkin (helen.larkin@deakin.edu.au) 
Despite this global shift in attitudes and policy in recent years, it is yet to transfer to a major shift in the education programs of architects and designers. Ostroff (2011) argued that there is "only a handful of universities around the world where universal design, or inclusive design, or design for all is even an elective within the professional curriculum" (p.1.9), and there remains a prevalence of architecturally designed environments around the world that continue to create disadvantage for many (Jones, 2014). It is therefore necessary to explore the attitudes of architects and designers to these global challenges. However, as noted by Hitch, Dell \& Larkin (2016), there are relatively few published studies around inclusive design curriculum delivered to architecture and design students during their professional training. Professional training is a key site for socialisation into a profession's values and practices, and previous research suggests that architects' anticipatory socialisation prior to entering the profession emphasises creativity over administrative or regulatory tasks (Sang et al., 2009). An understanding of the attitudes of architecture students towards inclusive and universal design can inform this aspect of the curriculum, by highlighting any misconceptions or incongruencies between their perspectives and desired professional values.

A handful of authors (for example, Altay \& Demirkan, 2013; Bernardi \& Kowaltowski, 2010; Chang et al., 2000; Evcil, 2012; Helvacioglu \& Karamanoglu, 2012; Larkin et al., 2013) have investigated the implementation of universal design into architecture and design curriculum in higher education as a means to encourage new graduates to utilise Universal Design Principles and to enhance the implementation in architectural practice. With an increasing demand on being sensitive to diverse user needs, it is important for upcoming architects to develop new abilities and attitudes towards design (Bernardi \& Kowaltowski, 2010). For this to occur, adequate training and education within the design curriculum is required. Many authors have supported this and argued the importance of universal design implementation in design curriculum (Bernardi and Kowaltowski, 2010; Evcil, 2012; Helvacioglu \& Karamanoglu, 2012; Olgunturk \& Demirkan, 2009; Paulsson, 2005; Watchorn et al., 2013). Bernardi and Kowaltowski (2010) provided further support, stating the curricula must adapt its focus in order to maintain architecture education that is relevant to current public and political debates. However little evidence exists demonstrating how to do this or the most effective methods to enhance attitudes to universal design.

The concept of universal design developed from the field of architecture, when Ronald Mace challenged conventional design approaches and provided a design foundation for products and environments that were more usable and accessible (Burgstahler, 2012). In 1989, Mace established the Centre for Universal Design at North Carolina State University (The Centre for Universal Design, 2008). Here, he worked with others to define universal design as the "design of products and environments to be usable by all people, to the greatest extent possible, without the need for adaption or specialized equipment" (Case 2003, p. 2). From the Centre, seven principles of universal design were established for application to product development and are displayed in Table 1. 
Table 1: Principles of Universal Design

\begin{tabular}{|c|c|}
\hline Principle & Descriptor \\
\hline (1) Equitable use & The design is useful and marketable to people with diverse abilities \\
\hline (2) Flexibility in use & $\begin{array}{l}\text { The design accommodates a wide range of individual preferences } \\
\text { and abilities }\end{array}$ \\
\hline $\begin{array}{l}\text { (3) Simple and intuitive } \\
\text { use }\end{array}$ & $\begin{array}{l}\text { Use of the design is easy to understand, regardless of the user's } \\
\text { experience, knowledge, language skills or current concentration } \\
\text { level }\end{array}$ \\
\hline $\begin{array}{l}\text { (4) Perceptible } \\
\text { information }\end{array}$ & $\begin{array}{l}\text { The design communicates necessary information effectively to the } \\
\text { user, regardless of ambient conditions or the user's sensory } \\
\text { abilities }\end{array}$ \\
\hline (5) Tolerance for error & $\begin{array}{l}\text { The design minimizes hazards and the adverse consequences of } \\
\text { accidental or unintended actions }\end{array}$ \\
\hline (6) Low physical effort & $\begin{array}{l}\text { The design can be used efficiently and comfortably and with a } \\
\text { minimum of fatigue }\end{array}$ \\
\hline $\begin{array}{l}\text { (7) Size and space for } \\
\text { approach and use }\end{array}$ & $\begin{array}{l}\text { Appropriate size and space is provided for approach, reach, } \\
\text { manipulation, and use regardless of user's body size, posture or } \\
\text { mobility }\end{array}$ \\
\hline
\end{tabular}

There remains limited research that explores architects' application of universal design during the design process and discussions predominantly revolve around issues and barriers to this application. Identified issues relating to universal design application include a lack of knowledge regarding universal design itself and a lack of an efficient and transparent manner for the dissemination of current research and knowledge (Heylighen, 2008), lack of an assessment or evaluation tool (Preiser, 2008) and lack of systematic procedures and priority recommendations (Afacan \& Demirkan, 2010; Preiser, 2008). Karol (2008) also briefly discussed the lack of universal design application due to limited consumer requests. The translation of universal design into architectural and design practice, therefore remains a vexed question (Jones, 2014)

In 2010, the Design 4 Diversity: Enhancing inter-professional learning for architecture and occupational therapy students initiative was undertaken at Deakin University, Geelong (Larkin et al., 2010a). The project focused on inter-professional education for architecture and occupational therapy students in relation to universal design practice. Key aims of the project were to; explore the perspective of key industry stakeholders; develop and trial flexible blended teaching and learning resources; provide rich experiences regarding inclusive design practice; and, to explore and identify sustainable opportunities for architecture and occupational therapy students to learn about inclusive design practice within a framework of inter-professional education (Larkin et al., 2010a). Findings from this 
project included the identification of major enablers and barriers to the uptake of universal design (Watchorn, Hitch, Larkin and Ang, 2014). In a pre and post-test study design, results of the evaluation of the Design 4 Diversity initiative showed that occupational therapy students were significantly more positive initially about the prospect of an inter-professional practice experience compared to their architecture student colleagues and while this trend continued at the end of the project, findings indicated that occupational therapy students actually became less positive in some areas (Larkin, Hitch, Watchorn \& Ang, (2013). Additional findings included that architecture and occupational therapy students when provided with 'real-life' versus Second Life ${ }^{\mathrm{TM}}$ simulations of disability, found the 'real-life' simulations more authentic and helpful (Watchorn, Larkin, Ang \& Hitch, 2013)

The aim of the study in this paper is to report on a follow-up study to the evaluations that were undertaken at the time as part of the 2010 Design 4 Diversity initiative. Given that the intent of the project was to attempt to influence the attitudes of architecture students both locally and internationally, this quantitative study aimed to measure the attitudes regarding universal design of those architecture students who participated in Design 4 Diversity and to compare and contrast them to the attitudes of a group of architecture students who were not part of the project. The specific research questions addressed in this study were: 1) What are the attitudes of architecture students to universal design; and 2) Is there a statistically significant difference in attitudes to the universal design of built environments between Group One and Group Two?

\section{Method}

This study used a quantitative quasi-experimental design, comparing two naturally occurring groups (Punch, 2005). Group One received the intervention (access to an inclusive design specific curriculum), while Group Two was a control group. Using this method the researcher was provided with descriptive data about the sample and a numerical representation of the attitudes of architecture students to the universal design of built environments.

\section{Sample}

The sample was recruited via purposive sampling from two separate population groups. Third and fourth year architecture students who had participated in the Design 4 Diversity program (Group One) and fifth year architecture students who had not participated in the program (Group Two). This method of sampling ensured participants were a representative sample for the study (Portney \& Watkins, 2009). Inclusion criteria for the study were:

- Students undertaking a Bachelor of Design (Architecture) at a large regional Australian University in their third year of study in 2013;

- Students undertaking a Master of Architecture and in their fourth or fifth year of study at a large regional Australian University in 2013;

- Students who began a Bachelor of Design (Architecture) at a large regional Australian university and have continued through the degree without a break and without studying at any other educational institution;

- Students aged 18 years and over; and,

- Students who are able to speak English to a level that supports study at university.

Participants were excluded from the study if they did not meet the above inclusion criteria. A total of 370 architecture students were enrolled in the targeted classes. Of these students, $147(39.7 \%)$ returned questionnaires. Another 13 were excluded as the participants did not meet the inclusion criteria or questionnaires were returned incomplete. This left a total of 134 
completed questionnaires and a response rate of $36.2 \%$. Of these, $82(64.9 \%)$ were completed by students in their third or fourth years of study (Group One) and 52 (38.8\%) were completed by students in their fifth year of study (Group Two). Respondents in Group One (students who had participated in Design 4 Diversity) comprised 53 males (64.6\%) and 29 females (35.4\%). Participant age ranged from 20 years to 58 years, with a mean age of 24.5 years $(S D=6.156)$. Participants in Group Two (students who had not participated) comprised of 34 males (65.4\%) and 18 females (34.6\%). Participant age ranged from 22 years to 48 years, with a mean age of 26.5 years $(S D=5.573)$.

\section{Instrument}

A questionnaire entitled An exploration of the attitudes of architecture students to the universal design of built environments was developed for the purpose of this study as none were in existence that met our needs. The questionnaire included a compilation of closed (51) and open (2) questions (both of which invited further comments in relation to the quantitative questions). It incorporated: the collection of demographic information; a standardised assessment (the Interaction with Disabled Persons Scale (IDP) (Gething, 1991)); an adaption of a published assessment in relation to universal design (the Universal Design Performance Measure for Products (The Centre for Universal Design 2000)); and specifically developed questions in relation to the importance of universal design, familiarity with the Australian Standards for Design for Access and Mobility (Standards Australia, 2009) and support for proposed visitability requirements. Results from the IDP from this sample have been published by Hitch, Dell and Larkin (2016). Pilot testing of the questionnaire with a group of nine research students from occupational therapy was conducted to identify any issues prior to the implementation of the questionnaire (Portney \& Watkins, 2009) and this did not reveal the need for any changes to be made. During the development of the questionnaire, double-barrelled questions were avoided to ensure each question was confined to a single idea (Portney \& Watkins, 2009). Please see Appendix 1 for a full copy of the questionnaire.

\section{Procedure}

\section{Ethics approval}

Prior to commencing this study, ethics approval was obtained from Deakin University (HEAG-H 79_2013)

\section{Participant recruitment}

Architecture students in the targeted classes received a brief oral presentation from the researcher, 20 minutes prior to the conclusion of the class. This presentation outlined the research project and invited architecture students to participate. The researcher had no prior relationship with the architecture students, which increased the likelihood of participation being completely voluntary by avoiding power-dependencies or coercion (Portney \& Watkins, 2009).

\section{Data collection}

Following the researcher's oral presentation to invite participant recruitment, a Plain Language Statement and a copy of the questionnaire were distributed to all students attending the class. The architecture students were allocated fifteen minutes of class time to complete the questionnaire. The second author was available to answer any questions relating to the study. A box to collect completed questionnaires was positioned by the exit of the room. Consent was assumed if participants returned their questionnaires, all information provided was anonymous, with only year of study provided by students. 


\section{Data analysis}

Following data collection, each questionnaire response was coded, the IDP scale was scored according to its manual and the sum of responses on the universal design scales were calculated. Demographic data obtained from the participants was also coded and entered. The second author visually checked $10 \%$ of the data to review accuracy of entry. Data were then analysed using the Statistical Package for Social Sciences (SPSS) Version 21.0.

\section{Demographic Data}

Quantitative demographic data obtained from the questionnaire were analysed using descriptive statistics to summarise the characteristics of each sample. Categorical data (e.g. sex and group) were analysed by total number and percentage of a given response, while continuous data (eg. age) were analysed by calculating the mean, standard deviation and range of the data.

\section{Hypotheses}

Descriptive statistics were used to analyse responses to questions relating to universal design to provide an overview of the scores obtained for each group. The distribution of the data was inspected using a histogram and did not conform to normality. Data were first analysed descriptively to gain an overview of how each group responsed to every specific question. A two-tailed Mann-Whitney U-Test was then performed to determine if there was a significant difference in attitudes to universal design between groups. This is a common form of analysis when parametric assumptions are not met and the sample contains two independent groups of subjects with a non-directional hypothesis (Portney \& Watkins, 2009). The Mann-Whitney U-Test variables are in Table 2 . The significance level was set to $p=<.05$.

Table 2: Variables utilised in Mann-Whitney U-Test

\begin{tabular}{|c|c|}
\hline Test & Variables \\
\hline 1 & Group One and Group Two overall scores of attitudes to universal design \\
\hline 2 & $\begin{array}{l}\text { Group One and Group Two total scores of attitudes to the universal design of } \\
\text { public buildings }\end{array}$ \\
\hline 3 & $\begin{array}{l}\text { Group One and Group Two total scores of attitudes to the universal design of } \\
\text { private buildings }\end{array}$ \\
\hline 4 & $\begin{array}{l}\text { Group One and Group Two scores to the importance of universal design to their } \\
\text { future professional career }\end{array}$ \\
\hline 5 & Group One and Group Two scores to the proposed visitability requirements \\
\hline
\end{tabular}

Data collected from one open question relating to the proposal of building visitability requirements were also transcribed. The process of analysis for this data involved printing a hard copy of the two separate groups' open responses and reading and re-reading the data to become familiar with it. Responses were then coded to identify common answers within the data. 


\section{Results}

\section{Attitudes to universal design}

On each of the scales measuring attitudes to the universal design of buildings and built environments, possible scores could range from 10-50. Tables 3 and 4 display the responses provided by each participant group - Group One and Group Two. The possible range of total scores of both universal design scales was 20-100 with Group One scores ranging from 33-100 (Mean $=77.29, \mathrm{SD}=13.87$ ) and Group Two scores ranging from 43-100 (Mean $=78.10, \mathrm{SD}=11.35)$. The statement around buildings being usable without sight attracted the lowest mean score from both Groups, while Group Two gave an equally low score to the statement that buildings and built environments should appeal to all potential users. The mean scores was highest for the statement that potential users of a private building should have access to all of its features regardless of their capability for both Groups, while Group Two also rated the statement regarding use of public buildings without stigma highly. In regards to attitudes to universal design, higher mean scores were given for statements related to buildings and built environments in the public space, than for those for private use. This suggests that architecture students viewed the universal design of public spaces more positively than the universal design of private spaces.

Table 3: Group One participant raw scores- Attitudes to universal design

$\begin{array}{llll}M & \text { SD } & \text { M } & \text { SD }\end{array}$

a. All potential users should be able to use a building or built environment in essentially the same way, regardless of differences in abilities

b. Potential users should be able to use a building or built environment without feeling stigmatised because of differences in personal capabilities

c. Potential users of a building should have access to all features of privacy, security, and safety regardless of capabilities

d. A building or built environment should appeal to all potential users

\begin{tabular}{llll}
\hline 4.15 & 0.8 & 3.68 & 1.0 \\
& 0 & & 4 \\
4.07 & 0.9 & 3.77 & 1.0 \\
& 8 & & 2 \\
& & & \\
$4.23^{*}$ & 0.8 & $3.94^{*}$ & 0.8 \\
& 2 & & 8 \\
4.18 & 0.8 & 3.74 & 1.0 \\
& 5 & & 8 \\
3.88 & 1.0 & 3.74 & 0.9 \\
& & & 7 \\
3.92 & 0.8 & 3.75 & 1.0 \\
& 4 & & 3 \\
& & & \\
& & &
\end{tabular}


g. A building or built environment should be able to be used without sight

h. A building or built environment should be able to be used by someone who is weak or tired or easily fatigues

i. It should be easy for a person of any size to see all the important elements of a building or built environment from an position (e.g. standing or seated)

j. There should be enough space to use a building or built environment with devices or assistance (e.g. wheelchair, oxygen tank, or service dog).

Total Score

$\begin{array}{lllll}3.73 & 0.9 & & 3.64^{* *} & 0.9 \\ & 0 & & & 7 \\ 3.77 & 0.9 & & 3.71 & 0.9 \\ & 2 & & & 6 \\ 3.84^{* *} & 0.8 & & 3.73 & 0.9 \\ & 7 & & & 3 \\ 4.07 & 0.9 & & 3.85 & 0.9 \\ & 7 & & 7 \\ 39.85 & 6.6 & & 37.44 & 8.1 \\ & 7 & & 9\end{array}$

Note. $\mathrm{M}=$ mean

$\mathrm{SD}=$ standard deviation

* $=$ highest mean score

** $=$ lowest mean score

Table 4: Group Two participant raw scores- Attitudes to universal design

\begin{tabular}{|c|c|c|c|c|}
\hline \multirow[t]{2}{*}{ Statement } & \multicolumn{2}{|c|}{ Public } & \multicolumn{2}{|c|}{ Private } \\
\hline & $M$ & SD & $\mathbf{M}$ & SD \\
\hline $\begin{array}{l}\text { a. All potential users should be able to use a building or built } \\
\text { environment in essentially the same way, regardless of } \\
\text { differences in abilities }\end{array}$ & 4.25 & 0.88 & 3.71 & 1.07 \\
\hline $\begin{array}{l}\text { b. Potential users should be able to use a building or built } \\
\text { environment without feeling stigmatised because of differences } \\
\text { in personal capabilities }\end{array}$ & $4.46^{*}$ & 0.64 & 3.94 & 0.83 \\
\hline $\begin{array}{l}\text { c. Potential users of a building should have access to all } \\
\text { features of privacy, security, and safety regardless of } \\
\text { capabilities }\end{array}$ & 4.21 & 0.78 & $4.00^{*}$ & 0.79 \\
\hline $\begin{array}{l}\text { d. A building or built environment should appeal to all potential } \\
\text { users }\end{array}$ & 4.42 & 0.78 & $3.62^{\star \star}$ & 1.17 \\
\hline $\begin{array}{l}\text { e. An untrained person should be able to use a building or built } \\
\text { environment without instructions }\end{array}$ & 3.90 & 1.14 & 3.83 & 1.04 \\
\hline $\begin{array}{l}\text { f. A building or built environment should be able to be used } \\
\text { without hearing }\end{array}$ & 3.96 & 0.84 & 3.90 & 0.89 \\
\hline $\begin{array}{l}\text { g. A building or built environment should be able to be used } \\
\text { without sight }\end{array}$ & $3.57^{* *}$ & 0.98 & $3.62^{\star *}$ & 0.95 \\
\hline $\begin{array}{l}\text { h. A building or built environment should be able to be used by } \\
\text { someone who is weak or tired or easily fatigues }\end{array}$ & 3.85 & 0.89 & 3.90 & 0.90 \\
\hline $\begin{array}{l}\text { i. It should be easy for a person of any size to see all the } \\
\text { important elements of a building or built environment from an } \\
\text { position (e.g. standing or seated) }\end{array}$ & 3.63 & 1.12 & 3.63 & 1.11 \\
\hline $\begin{array}{l}\text { j. There should be enough space to use a building or built } \\
\text { environment with devices or assistance (e.g. wheelchair, }\end{array}$ & 4.15 & 0.85 & 3.75 & 1.02 \\
\hline
\end{tabular}


oxygen tank, or service dog).

Total Score

$\begin{array}{llll}40.42 & 5.75 & 37.67 & 7.49\end{array}$

Note. $\mathrm{M}=$ mean

$\mathrm{SD}=$ standard deviation

* = highest mean score

$\star *=$ lowest mean score

\section{Relevance to future professional practice}

Descriptive statistics were calculated for one question relating to the level of valued importance of universal design knowledge for their future professional practice. This question was based on a 5-point Likert Scale with 1 being Not at all important to 5 being Extremely important. Group One sored a mean of $4.33(\mathrm{SD}=0.8)$ indicating most participants considered it to be Very important or Extremely important to their future professional career. Group Two scored a mean of $4.51(\mathrm{SD}=0.59)$ also indicating most participants considered it to be Very important or Extremely important.

\section{Familiarity with Australian Standards}

Descriptive statistics were calculated for one question relating to reported familiarity with the Australian Standards AS 1428.1-2009 Design for Access and Mobility (Australian Standards, 2009). This question was based on a 5-point Likert Scale with 1 being I have never heard of the Standards to 5 being I am very confident in my knowledge of the Standards. Frequencies of scores for this question are presented in Table 5. Response 4; "I am familiar with some aspects of the Standards" was the most frequently chosen response with 29 of 78 Group One participants. Frequencies of scores for Group Two are also presented in Table 5. Response 4; "I am familiar with some aspects of the Standards" was again, the most frequently chosen response with 17 of 51 participants who responded to this question selecting this option.

Table 5: Participant raw scores- Familiarity with Australian Standards

\begin{tabular}{|c|c|c|c|c|}
\hline \multirow{2}{*}{ Response } & \multicolumn{2}{|c|}{ Group One } & \multicolumn{2}{|c|}{ Group Two } \\
\hline & $\mathbf{n}$ & $\%$ & $\mathbf{n}$ & $\%$ \\
\hline 1 I have never heard of the standards & 7 & 9.0 & 4 & 7.8 \\
\hline $\begin{array}{l}2 \text { I have heard of the standards but have never } \\
\text { seen them }\end{array}$ & 12 & 15.4 & 10 & 19.6 \\
\hline $\begin{array}{l}3 \text { I have looked at or read the standards but } \\
\text { am able to recall very little of the information }\end{array}$ & 25 & 32.1 & 14 & 27.5 \\
\hline $\begin{array}{l}4 \text { I am familiar with some aspects of the } \\
\text { Standards }\end{array}$ & 29 & 37.2 & 17 & 33.3 \\
\hline $\begin{array}{l}5 \text { I am very confident in my knowledge of the } \\
\text { Standards }\end{array}$ & 5 & 6.4 & 6 & 11.8 \\
\hline Total & 78 & 100 & 51 & 100 \\
\hline
\end{tabular}

\section{Attitudes to visitability}

These results relate to one question relating to support for the implementation of a number of visitability requirements for the design of all new private homes and residences. Participants were required to select one of three options with 1 being Mandatory, 2 being Aspirational target and 3 being Should not be considered. Group One scored a mean of 1.81 
$(\mathrm{SD}=0.69)$ indicating most participants thought the visitability requirements should be implemented as mandatory or aspirational targets. Group Two scored a mean of 1.81 $(S D=1.74)$ also indicating most participants thought the visitability requirements should be implemented as mandatory or aspirational targets.

Analysis of responses provided via further comments to the question was also completed to provide greater insight into architecture student attitudes to universal design of buildings and built environments. Due to the limited number of comments, this review was undertaken as an entire sample, rather than separating the two groups. Content analysis was used to understand the contents of these comments, with the responses coded individually and these codes then grouped into themes. Forty-five (35.4\%) participants suggested these requirements should be mandatory, 67 (52.8\%) suggested they should be utilised as an aspirational target and $13(10.2 \%)$ participants stated their implementation should not be considered. Analysis of comments indicated four key themes. These were: emerging: concerns relating to cost and expenses; importance of tailoring to the client; general suggestions why it may not work; and, general support for the implementation.

In relation to cost and expenses, one participant stated: "Overdesigning for the sake of making the residence accessible in the future, just in case, is an unnecessary cost" (Group One participant). Examples of comments relating to the need to tailor designs to the client included: "Private homes should be designed to the individual" (Group Two participant) and "It essentially boils down to catering for the client" (Group One participant). In relation to the ineffectiveness of visitability requirements, one participant stated: "Legislation restricts design, resulting in negative impacts the 'requirements' did not intend" (Group Two participant). Finally, the following comment captures the general support found within this data for the implementation of visitability requirements:

"I think it is best for these items to be mandatory as it makes it a lot easier when people move into new houses or change homes for particular reasons. This would allow the home to be adapted appropriately to suit the person moving In" (Group One participant).

\section{Comparison of Group One and Group Two}

A two-tailed Mann-Whitney U-Test was performed to determine if there was a statistically significant difference between the two groups. The results of these analyses are reported in Table 6. As demonstrated by this table, there were no significant differences identified between the two groups on: total scores for the attitudes towards the universal design of public buildings and built environments scale; the attitudes towards the universal design of private buildings and built environments scale; overall scores on the universal design scales; scores on the importance of universal design to participant future professional career; scores to the proposed visitability requirements; or, scores on familiarity with the Australian Standards.

Table 6: Comparison of Group one and Group Two- Universal Design

UD-Public UD-Private UD-Total UD- Visitability AS
Importance Requirements Familiarity

\begin{tabular}{ccccccc}
\hline $\begin{array}{c}\mathbf{p} \\
\text { value }\end{array}$ & .909 & .865 & .951 & .278 & .621 & .827 \\
\hline
\end{tabular}

Note. UD-Public=Attitudes to universal design of public buildings and built environments UD-Private=Attitudes to universal design of private buildings and built environments UD-Total=Total of both attitudes to universal design scales 
UD-Importance=Valued importance of universal design to participant future professional career

Visitability Requirements=Support for implementation of proposed visitability requirements AS Familiarity=Familiarity with the Australian Standards 1428.1 - 2009 Design for Access and Mobility

However, a statistically significant difference was identified on Question B of the attitudes to the universal design of public buildings and built environments measure; potential users should be able to use a building or built environment without feeling segregated or stigmatised because of differences in personal capabilities $(U$-Test $=.019, p<.05)$. Group Two scored higher on the raw scores of this item (4.46) than Group One (4.07) indicating Group Two had more positive attitudes to universal design than Group One on this item.

An Analysis of Covariance (ANCOVA) was also completed for the entire sample to identify any confounding variables. Age, gender, personal experience of a temporary or permanent health condition and knowing someone with a permanent or temporary health condition were not identified as factors influencing attitudes to universal design.

\section{Discussion}

Results of data analysis have provided initial insights into the attitudes of architecture students to universal design, an area that has not been explored in previous studies. Overall, relatively positive attitudes were measured across both groups of architecture students. Notably, Item G "A building or built environment should be able to be used without sight" had the lowest mean score indicating less positive attitudes to this item, despite one of the simulation activities used within the universal design curriculum being the use of glasses to imitate a vision impairment (Larkin et al., 2010a). Empirical literature relating to teaching universal design in Brazil has supported this strategy to enhance student awareness and sensitivity (Bernardi \& Kowaltowski, 2010). A focus on vision impairment as a basis for education about universal design also appears to be a theme within the empirical literature. Authors from Belgium and Sweden report on the inclusion of users as experts, commonly with some form of vision impairment, to assist students' understanding and evaluation of designs (Heylighen et al., 2009; Paulsson, 2005). Considering this consistent inclusion of vision impairment throughout the empirical universal design teaching literature, it is unclear why participants viewed this item less positively.

Overall, architecture students had positive attitudes to the universal design of buildings and built environments. This was highlighted through responses to the valued importance of universal design knowledge to their future professional careers in which students considered it to be either "Very" or "Extremely important". Positive attitudes were also noted on specific items of the scale used to measure attitudes to universal design. These items included; "Potential users of a building or built environment should have access to all features of privacy, security, and safety regardless of personal capabilities", "A building or built environment should appeal to all users", "There should be enough space to use a building or built environment with devices or assistance (e.g. wheelchair, oxygen tank, or service dog)" and "Potential users should be able to use a building or built environment without feeling stigmatised because of differences in personal capabilities". This finding supports the continued inclusion of universal design teaching as a valuable aspect of curriculum within architecture higher education, despite there being no quantitative difference between the groups. Architecture students were also noted to view the universal design of public buildings and built environments more positively than the universal design of private buildings or built environments. Due to the confines of this study, it was not possible to explore this finding further. However it could be hypothesised that students believe they are 
'designing for all' when working on public buildings and built environments, however when working on private buildings they are designing specifically for the needs of the client and the client's requests.

Further comments relating to four proposed visitability requirements for the new building work of private buildings also provide interesting insights into architecture student perspectives on the matter. While there was some general support for their implementation, a number of students discussed their disagreement, highlighting that the requirements would provide unnecessary or unwarranted costs during the building process and that clients should have the opportunity to decide for themselves. It is clear at this current time, that architecture students view the priority of visitability as a significant expense, indicating a need for further research into the cost comparison of designing with universal design principles or later retrofitting. These findings also suggest further education is required to enhance architecture student attitudes and the profession in general, to universal design and visitability and to highlight universal design as a key selling point of future designs, in much the same way as energy and sustainability codes. While architecture students in general expressed an overall degree of familiarity with the local standards, it is well recognised that such standards are complex in their implementation and only represent a starting point for a design process that attempts to be inclusive. Larkin, Hitch, Watchorn and Ang (2015) emphasised that visitabiliy or accessibility requirements do not equate with design that is truly inclusive and at the heart of universal design.

On the whole, however, this study did not find statistically significant differences between the two groups of students on the measure of attitudes to universal design that was used. Extensive empirical literature exists that identifies important features when teaching architecture students about universal design. Bernardi and Kowaltowski (2010) suggested that role-playing of individuals with motor, vision and hearing difficulties was essential to increasing architecture student's perspectives and awareness of universal design. Further to this, Paulsson (2005) discussed the need for collaborative projects with users, experts, partners and other schools as well as the need for staff who are champions and leaders of change. Olgunturk and Demirkan (2009) also recommended universal design implementation as both a separate course as well as within design studios in the Turkish context. These recommendations are consistent with the content and strategies of the Design 4 Diversity program suggesting it was based on the best available current evidence, regardless of the fact that significant differences were not generally found.

Pre- and post- results from the Design 4 Diversity project reported by Larkin et al. (2010b) also suggested a trend toward improved architecture student familiarity with the Principles of Universal Design. These results are consistent with findings from a six-week Amercian teaching program in which junior-level interior design students were asked to incorporate the universal design concept when redesigning housing units for students with disabilities (Chang et al., 2000). Similar teaching methods to those recommended within the literature were utilised. Chang et al. (2000) found a significant difference in knowledge of the Universal Design Principles from the overall means obtained from the pre and post- tests. These findings suggest that both programs, which implemented strategies according with the current evidence, were effective in enhancing architecture students' knowledge of universal design in the short term. However, this literature does not investigate important features of programs to change or enhance the attitudes of architecture students to universal design. Bernardi and Kowaltowski (2010) recognised "this is needed to develop teaching methods to change future design professionals' attitudes" (p. 387). This lack of evidence and understanding may explain why no significant difference on attitudes to universal design was found between the two groups, as strategies to increase the knowledge of universal design 
may not be the same as strategies needed to improve or enhance student attitudes to this design concept.

Paulsson (2005) also identified that learning Universal Design Principles is a process and requires some time. However, the literature currently lacks any longitudinal or follow-up studies to determine the long-term retention and application of this knowledge. As discussed earlier, Chang et al. (2000) reported on a six-week pre- and post-test research design. Bernardi and Kowaltowski (2010) reported on a semester-long program that aimed to develop the awareness and sensitivity of students. Olgunturk and Demirkan (2009) also reported on a semester-long, 14-week elective course with content relating to diversity and the Universal Design Principles. Finally, as part of the Design 4 Diversity initiative, Watchorn et al. (2013) also reported on the semester-long program in which data were collected in a pre- and post-test design. While a number of studies from around the world have been identified evaluating the effectiveness of their education programs, this current study appears to be the first to collect data at a period of time after completion of the program. It is therefore difficult to confirm ensuring long-term retention and application of universal design knowledge. However, regardless of the similarity in response between the two groups, there was a generally positive view by architecture students towards the universal design of buildings and built environments.

\section{Limitations}

There were a number of limitations associated with this study. As the questionnaire was voluntary, there was the potential for a self-selection bias where students particularly interested in the topic may be more likely to participate. However, due to ethical issues, the questionnaire could not be made mandatory. Due to the nature of the study and the setting in which it was conducted, it was not possible to ensure all participants completed the questionnaire independently without discussing with their peers. Therefore it is not possible to determine if leakage may have occurred and how this may have impacted on results. The generalisability of the study is also limited. Purposive sampling was utilised to ensure a representative sample for the study. However, this also meant that the sample, which was from one university in Australia, is not generalisable to the architecture student population. Given that this was a relatively small-scale study conducted within the context of an undergraduate Honours study, this was accepted as appropriate.

\section{Recommendations for further research}

It would be valuable for future studies to include a qualitative aspect allowing for greater indepth understanding of architecture student attitudes to universal design in the longer term, particularly post-graduation and in the context of professional practice. It would also be beneficial to complete a longitudinal or follow-up study to investigate the retention and application of knowledge long-term. A study comparing the associated costs of designing with universal design in mind and the costs associated with retrofitting buildings at a later stage would also be beneficial.

\section{Conclusion}

While existing research has evaluated the implementation of universal design teaching programs within architecture higher education, this study is the first to assess architecture student attitudes to universal design at a period in time post-completion of the program. Despite the lack of significant differences between the two groups of architecture students, this study still provides valuable insights into their attitudes to universal design, an area not 
previously investigated. These findings have contributed to the current body of knowledge relating to universal design in higher education and have identified important areas for future research in order to enhance the training and education of future architects. 


\section{References}

Afacan, Y. \& Demirkan H. (2010). A priority-based approach for satisfying the diverse users' needs, capabilities and expectations: A universal kitchen design case. Journal of Engineering Design, 21(2-3), 315-343.

Altay, B. \& Demirkan, H. (2014). Inclusive design: Developing students' knowledge and attitude through empathic modelling. International Journal of Inclusive Education, 18(2), 196-217.

Bernardi, N. \& Kowaltowski, D. (2010). When role playing is not enough: Improved universal design education. International Journal of Architectural Research, 4(2-3), 376-390.

Burgstahler, S. (2012). Universal design in education: Principles and applications, Retrieved from http://www.washington.edu/doit/universal-design-education-principles-andapplications

Case, J. (2003), Universal Design, Retrieved from http://images.pearsonassessments.com/images/tmrs/tmrs_rg/UniversalDesign.pdf?W T.mc_id=TMRS_Universal_Design

Chang, B.V., Tremblay, K.R., \& Dübar, B.H. (2000). An experiential approach to teaching universal design. Education, 121(1), 153-158.

Connell, B.R. (1997). Principles of Universal Design, Retrieved from http://www.ncsu.edu/ncsu/design/cud/about ud/udprinciplestext.htm

Evcil, A. (2012). Raising awareness about accessibility. Procedia - Social and Behavioural Sciences, 47, 490-494.

Gething, L. (1991). Interaction with Disabled Persons Scale: Manual and kit, University of Sydney: Sydney.

Helvacioglu, E. \& Karamanoglu, N. (2012). Awareness of the concept of universal design in design education. Procedia - Social and Behavioural Sciences,51, 99-103.

Heylighen, A. (2008). Sustainable and inclusive design: A matter of knowledge? Local Environment, 13(6), 531-540.

Heylighen, A., Herssens, J., \& Froyen, H. (2009), Architecture criticism blindfolded, Retrieved from https://lirias.kuleuven.be/bitstream/123456789/206651/2/09IncludeHeylighen.pdf.pdf.

Hitch, D., Dell, K. \& Larkin. H. (2016). Does universal design education impact on the attitudes of architecture students towards people with a disability? Journal of Accessibility and Design for All, 6(1), 26-48.

Jones, P. (2014). Situating universal design architecture: Designing with whom? Disability and Rehabilitation, 36(16), 1369-1374. doi: 10.3109/09638288.2014.944274

Karol, E. (2008). Inclusive design and the new home market: The West Australian situation. Architectural Science Review, 51(1), 80-83.

Larkin, H., Ang, S., Watchorn, V., Segrave, S., McCracken, M., Elkadi, H., \& Holt, D. (2010a). Design 4 Diversity enhancing inter-professional learning for architecture and occupational therapy students: Literature review. Deakin University: Geelong, Australia.

Larkin, H. Ang, S., Watchorn, V., Segrave, S., McCracken, M., Elkadi, H., \& Holt, D. (2010b). Design 4 Diversity enhancing inter-professional learning for architecture and occupational therapy students: Study findings. Deakin University: Geelong, Australia.

Larkin, H., Hitch, D., Watchorn, V., Ang, S., \& Stagnitti, K. (2013). Readiness for interprofessional learning: A cross-faculty comparison between architecture and occupational therapy students. Journal of Interprofessional Care, 27(5), 413-419.

Larkin, H., Hitch, D., Watchorn, V., \& Ang, S. (2015). Working with policy and regulatory 
factors to implement universal design in the built environment: The Australian experience. International Journal of Environmental Research and Public Health, 12, 8157-8171.

National People with Disabilities and Carer Council. (2009). Shut Out: The experience of people with disabilities and their families in Australia. Canberra: Commonwealth of Australia.

Olgunturk, N. \& Demirkan, H. (2009). Ergonomics and universal design in interior architecture education. Middle Eastern Technical University Journal of the Faculty of Architecture, 26(2), 123-138.

Ostroff, E. (2011). Universal design: An evolving paradigm. In W Preiser \& K.H. Smith (eds.). Universal design handbook ( $2^{\text {nd }}$ ed.) (pp. 1.3-1.11). NY: McGraw-Hill Education.

Paulsson, J. (2005). Universal design education project - Sweden. Retrieved from http://www.accessiblebuildings.eu/UserFiles/File/Budapest/Paper.2006.08.23.Jan.P.Budapest.pdf

Portney, L. \& Watkins, M. (2009). Foundations of clinical research applications to practice. Pearson: New Jersey.

Preiser, W. (2008). Universal design: From policy to assessment research and practice. International Journal of Architectural Research, 2(2), 78-93.

Punch, K. (2005). Introduction to social research quantitative and qualitative approaches. SAGE: London.

Sang, K., Ison, S., Dainty, A., \& Powell, A. (2009). Anticipatory socialisation amongst architects: A qualitative examination. Education + Training, 51(4), 309-321. Standards Australia. (2009). AS 1428.1 - 2009 Design for access and mobility, Part 1: General requirements for access - New building work. Retrieved from http://infostore.saiglobal.com/store/details.aspx?ProductID=1378917

The Centre for Universal Design. (2000). Universal Design Performance Measures for Products. The Centre for Universal Design: North Carolina.

The Centre for Universal Design. (2008). The Centre for Universal Design environments and products for all people. Retrieved from http://www.ncsu.edu/ncsu/design/cud/index.htm

United Nations (2006). Convention on the Rights of Persons with Disabilities. New York: United Nations. Retrieved from https://www.un.org/development/desa/disabilities/convention-on-the-rights-ofpersons-with-disabilities/the-convention-in-brief.html

Watchorn, V., Larkin, H., Hitch, D., \& Ang, S. (2014). Promoting participation through the universal design of built environments: Making it happen. Journal of Social Inclusion, 5(2), 65-88.

Watchorn, V., Larkin, H., Ang, A., \& Hitch, D. (2013). Strategies and effectiveness of teaching universal design in a cross-faculty setting. Teaching in Higher Education, 18(5), 1-14.

World Health Organization. (2002). Towards a common language for functioning, disability and health: ICF The International Classification of Functioning, Disability and Health. World Health Organization: Geneva.

World Health Organization. (2013). International Classification of Functioning, Disability and Health (ICF), Retrieved from http://www.who.int/classifications/icf/en/ 


\section{Biographical Notes}

Helen Larkin brings to academic position as senior lecturer in the occupational therapy program, over 30 years' experience in the disability sector in service provision, management and research. Her teaching and research interests includes curriculum development, interprofessional education, reflective practice and work integrated learning. Helen's contribution has been recognised through both university and national teaching awards.

Kelsey Dell was formerly an honours student in the Bachelor of Occupational Therapy, achieving a high distinction for her final thesis. She is now employed as an occupation therapist in Tasmania.

Dr. Danielle Hitch is a senior lecturer in the Deakin University occupational therapy program. She worked clinically in both the United Kingdom and Australia for over a decade. Her areas of interest include mental health, knowledge brokerage, inclusive education and social justice. 